ALPHA No 29 Diciembre 2009 (271-283)

ISSN 0716-4254

http://alpha.ulagos.cl

\title{
ESCENARIOS Y PERSONAJES DE ROBERTO BOLAÑO EN EL ENTORNO POSMODERNO
}

\author{
Juan Carlos Pino Correa* \\ Alexander Buendía Astudillo**
}

\section{SIEMPRE LOS MUROS}

Sobre el muro lateral de un edificio vecino vio un mural que le pareció curioso. Era circular, como un reloj, y donde debían estar los números había escenas de gente trabajando en las fábricas de Detroit. Doce escenas que representaban doce etapas en la cadena de producción. En cada escena, sin embargo, se repetía un personaje: un adolescente negro, o un hombre negro largo y esmirriado que aún no había abandonado o que se resistía a abandonar su infancia, vestido con ropas que variaban con cada escena pero que indefectiblemente siempre le quedaban pequeñas, y que cumplía una función que aparentemente podía ser tomada como la del payaso, el tipo que está ahí para hacernos reír, aunque si uno lo miraba con más atención se daba cuenta de que no sólo estaba allí para hacernos reír. Parecía la obra de un loco. La última pintura de un loco. En el centro del reloj, donde convergían todas las escenas, había una palabra pintada con letras que parecían de gelatina: miedo (Bolaño, 2666:307).

Así están las cosas, parece que quisiera decir —en esta cita- el escritor chileno Roberto Bolaño con esta representación desgarrada de un hombre del mundo actual o, mejor, del hombre de hoy. Así están las cosas cuando la historia de la humanidad llega a este punto, colmada de pasos en que se ha esgrimido siempre el deseo de desarrollo en una acepción más economicista del término y que, a veces, o casi siempre, lleva implícito un "a cualquier precio", un "a toda costa” o un "hasta las últimas consecuencias”. Pero ¿Por qué presentar, aquí, el mensaje a través de una representación pictórica anónima? ¿Por qué un mural en una calle de un barrio de pensionados (que podría ser de cualquier tipo de personas) y no una pintura en algún museo? ¿Por qué un hombre negro? ¿Por qué un reloj y una cadena de producción? ¿Por qué la repetición del hombre con su vestido pequeño, cual si repetición y vestido fueran una condena? ¿Por qué la risa, la locura? ¿Por qué la palabra miedo? ¿Qué hay de oculto y qué de evidente en tal mural? 


\section{Juan Carlos Pino - Alexander Buendía}

Las construcciones más elevadas de las ciudades de hoy son los edificios a los que se admira con el mismo arrobo que aún provoca la majestuosidad de las iglesias. Pero este edificio de Bolaño donde aparece el mural no es nada extraordinario. Su arquitectura no es llamativa, es sólo un edificio como hay muchos y que han desplazado a las casas y a los vecindarios de antaño. Es un edificio donde algunos escriben grafittis cada vez menos contestatarios desde la perspectiva política (Lejos está París del 68) o donde seres anónimos pueden pintar un mural para intentar convocar al transeúnte que pasa y que, cada vez, va más distraído intentando llegar pronto a casa para ver un partido de fútbol, una serie de televisión, jugar PC games en familia, leer un best seller de literatura o de superación personal o chatear con conocidos y desconocidos. Esas edificaciones de hoy son la prueba fehaciente de la mutación del espacio urbano que termina siendo vivido de manera diferente por las personas y donde se pueden observar desde vallas con publicidad de todo tipo - encargada a prestigiosas agencias - hasta murales populares pintados con los dedos a la vuelta de alguna esquina o en el espacio vacío donde probablemente se levante, en el futuro, otro edificio más destacado por su funcionalidad que por su estética.

Sobre ese mural que representa un reloj, los elementos de la naturaleza pasan una y otra vez y lo destiñen las miradas pasan y resbalan de manera desprevenida (con excepción de la mirada del periodista negro que lo observa en 2666). Y pasa el tiempo implacable aunque es probable que ese transcurrir sólo sea una ficción y que, por el contrario, el tiempo no pase ni en sus doce escenas horarias ni en la realidad que representan las escenas porque allí los hombres pueden estar encarnando a Sísifos modernos que en el subir y descender de la montaña con su piedra pueden ser imaginados dichosos, como lo propone Camus, pero también pueden ser imaginados al estilo griego: sometidos a un trabajo sin esperanza ¿De qué depende una posibilidad u otras? Podría decirse que de la consciencia de sus cadenas y/o de la consciencia de alguna utopía. $\mathrm{O}$, también, de las inconsciencias. Si la consciencia es de una condena se hace inevitable indagar cuál ha sido el delito o el daño cometido (el pecado, dirían algunos, aún) para merecer un castigo tan desmesurado. Y si la consciencia es de alguna utopía (una improbable utopía) la pregunta será por la forma como puede llegar a concretarse esa dicha soñada o prometida en un mundo ilusorio y seductor. Y unas ideas y otras se cernirán incesantes sobre la cabeza de las personas, acaso sin dar tregua para nada más, como si sólo quedara la hora de las simultaneidades. "Todo ha llegado a marcar la misma hora en el gran reloj del desarrollo o de la racionalización (al menos desde la perspectiva de Occidente)", afirma Fredric Jameson (1996: 232). 


\section{Escenarios y personajes de Roberto Bolaño en el entorno posmoderno}

En esas circunstancias, no sería extraño pensar una lectura de la escena de Bolaño en el sentido de que en el capitalismo de hoy - representado en el proceso industrial de aquel mural- el obrero (o el empleado, o el asalariado, o cualquier otro hombre que represente la subalternidad) cumple con su papel $\mathrm{y}$, a veces, parece un payaso triste creyendo ser feliz, absorbido por los conjuros de una sociedad de la información que lo hipnotiza a cada momento con sus referentes seductores. De esa sociedad, primero moderna y después posmoderna que le ha destruido el vecindario - que tanto disfrutaron en los siglos pasados sus antecesores - reemplazándolo con edificios donde también hay vecinos que él sabe que están, por supuesto, como una sombra muda alrededor; pero que, en realidad, no están porque sólo los encuentra por casualidad en las escaleras o en el ascensor y apenas cruza con ellos un saludo sin que nadie sepa los nombres, las profesiones o el estado civil. Bolaño quiere decirnos que los actos o creaciones de los hombres, llámense vivienda o vestido, o de cualquier otra manera, no se ajustan ("le quedan pequeñas", independientemente de cuál sea el diseño y el color) al carácter innegablemente humano que tienen todos los hombres, haciendo valer aquí la redundancia y la perogrullada, ni se ajustan a lo que ellos esperan de sí mismos y de los demás. Quizás, aquel hombre negro haga reír de alegría justamente a los señores que se nutren de su quehacer de horario rígido o a los babbits ${ }^{1}$ que terminan comprando compulsivamente y disfrutando los bienes tangibles e intangibles que él contribuye a elaborar en aquella cadena productiva. Pero, es posible que haya, también, algún transeúnte que lo mire como el símbolo de una época que va más allá de la simple industrialización y que acentúa su voracidad e inconmensurabilidad dejando enormes fisuras en lo que muchos llaman el estado de bienestar. Por ese carácter es que el hombre no ha podido dejar definitivamente atrás la infancia, aquella época paradisíaca donde se tejen los sueños que luego se resisten a morir frente a las máquinas cada vez más avanzadas del desarrollo contemporáneo y que, paradójicamente, revive insistente en producciones cinematográficas que observa en el teatro o en la televisión. De ahí la palabra "miedo" escrita en el centro de las imágenes: el miedo del hombre a perder su esencia, el miedo a no ser tratado como tal, el miedo a ser condenado a un trabajo sin esperanza, el miedo a perder los sueños que ahora parecen deshacerse en jirones y que puede empujar, por ejemplo, a un pintor a cortarse la mano derecha - la mano con que pinta- y convertirla en el summum de su obra, para que perdure, para que aumente su

\footnotetext{
${ }^{1}$ Fredric Jameson usa este término en alusión al protagonista de una novela del mismo título escrita por Sinclair Lewis y en referencia a aquellas personas "autosatisfechas que adoptan sin dudar los ideales conformistas de la clase media”, en El giro cultural: escritos seleccionados sobre el posmodernismo 1983-1998. Buenos Aires: Manantial, 2002:41.
} 
Juan Carlos Pino - Alexander Buendía

valor de cambio, tal como le sucede a Edwin Johns en otra de las escenas de 2666. Así es el siglo XX.

\section{CIEGOS ENTRE TANTA IMAGEN}

La escena a la que Bolaño se refiere retrata en toda su dureza uno de los procesos más significativos de la última centuria: la producción industrial cada vez más avanzada tecnológicamente; más propicia para elevar las plusvalías en el entramado económico multinacional. Pero, también, Bolaño retrata como en La literatura nazi en América a esta centuria con ironía y sarcasmo en otros momentos donde aparecen aquellos personajes que marcaron de manera dolorosamente significativa la historia de la humanidad

En 1929, mientras el crac mundial obliga a Sebastián Mediluce a retornar a Argentina, Edelmira y sus hijos son presentados a Adolfo Hitler, quien cogerá a la pequeña Luz y dirá: "Es sin duda una niña maravillosa”. Se hacen fotos. El futuro Führer del Reich causa en la poetisa argentina gran impresión. Antes de despedirse le regala algunos de sus libros y un ejemplar del Martín Fierro, obsequios que Hitler agradece calurosamente obligándola a improvisar una traducción al alemán allí mismo, cosa que no sin dificultad consiguen entre Edelmira y Carozzone. Hitler se muestra complacido. Son versos rotundos y que apuntan al futuro. Edelmira, feliz, le pide consejo sobre la escuela más apropiada para sus dos hijos mayores. Hitler sugiere un internado suizo, aunque apostilla que la mejor escuela es la vida. Al terminar la entrevista, tanto Edelmira como Carozzone se confesarán hitlerianos convencidos (2005:16).

El Martín Fierro, el héroe rebelde, el canto de la argentinidad, se queda en manos de Hitler mientras sus poetas aduladores se van a escribir obras que con otras conformarán la literatura nazi de América, una literatura ciega a los designios nefastos de su inspirador y a las iniquidades cotidianas, como ciegos son muchos personajes que van y vienen en el mundo fragmentado de Bolaño que trasiega por el siglo XX. Y son ciegos en el sentido de su incapacidad para percibir el carácter humano en sus múltiples dimensiones desde esta perspectiva. Así podría calificarse - en Nocturno de Chile - al poetaasesino del Chile de Pinochet (Alberto Ruiz-Tagle se hacía llamar, pero su nombre era Carlos Wieder) al torturador que ejecuta su trabajo en el sótano de una casa mientras su esposa hace de anfitriona en la sala, ante escritores e intelectuales embebidos en amena tertulia y a las autoridades de Santa Teresa —en 2666 - quienes, después de buscar un chivo expiatorio para los centenares de asesinatos de mujeres trabajadoras, manifiestan que "todo lo que a 


\section{Escenarios y personajes de Roberto Bolaño en el entorno posmoderno}

partir de ahora suceda entra en el rubro de los crímenes comunes y corrientes, propios de una ciudad en constante crecimiento y desarrollo" (673) lo que equivale a decir: daños colaterales y nada más o, lo que es lo mismo, "muertes habituales, sí, las usuales, gente que empezaba festejando y terminaba matándose, muertes que no eran cinematográficas, muertes que pertenecían al folclore pero no a la modernidad: muertes que no asustaban a nadie” (675). Pero ellos no son los únicos. También podrían entrar en esa categoría el joven barcelonés, de fanático de Joyce y su novia sudamericana que entran sin placer y sin remordimientos en el mundo de la delincuencia (Consejos de un discípulo de Morrison a un fanático de Joyce); el chileno que termina de profesor de gimnasia en Cataluña luego de estar vinculado con las actividades de la mafia rusa (como ocurre en La nieve); y en 2666 a la esposa de Amalfitano que trasiega sin rumbo fijo y visita en un manicomio a un poeta loco con quien cree haber hecho el amor, y a los lectores y críticos que no encuentran al misterioso escritor alemán que nunca se ha dejado ver (2666); la mujer que observa obsesivamente a un hombre en la televisión y que con intenciones apocalípticas lo amordaza después en su casa y le confiesa, en medio de la desolación total, en medio de la rabia total, que "las mujeres son putas asesinas, Max, son monos ateridos de frío que contemplan el horizonte desde un árbol enfermo, son princesas que te buscan en la oscuridad, llorando, indagando las palabras que nunca podrán decir” (2005:122-123). Y como ellos, hay muchos más. Aunque puede existir la posibilidad de que la ceguera, a la que aquí se hace referencia, no sea sino otra forma de lucidez (a diferencia de la manera como la aborda Saramago para quien la ceguera es caída y es desilusión, en todas las concepciones posibles: pérdida de las utopías, pérdida de la capacidad de amar, carencia de solidaridad). De malvada lucidez, la calificaría un juez, un periodista, un sacerdote o cualquier otro moralista. Pero esa es una posibilidad, apenas.

\section{EL ABURRIMIENTO Y EL HORROR INEVITABLES}

De lo que no queda duda, para el Bolaño que retoma a Baudelaire, es que el aburrimiento y el horror habitan el mundo y están íntima e indisolublemente ligados. Y en ello insiste casi obsesivamente, como en Literatura + enfermedad = enfermedad, uno de los textos contenidos en El gaucho insufrible

En medio de un desierto de aburrimiento, un oasis de horror. No hay diagnóstico más lúcido para expresar la enfermedad del hombre moderno. Para salir del aburrimiento, para escapar del mundo muerto, lo único que tenemos a mano, y no tan a mano - también en esto hay que esforzarse - es el horror, es decir, el mal. O vivimos como zombis, como esclavos alimentados con zoma, o nos convertimos en esclavi- 
Juan Carlos Pino - Alexander Buendía

zadores, en seres malignos, como el tipo aquel que después de asesinar a su mujer y a sus tres hijos dijo - mientras sudaba a mares- que se sentía extraño, como poseído por algo desconocido, la libertad, y luego dijo que las víctimas se habían merecido lo que les pasó, aunque al cabo de unas horas, más tranquilo, dijo que nadie se merecía una muerte tan cruel y luego añadió que probablemente se había vuelto loco y les pidió a los policías que no le hicieran caso. Un oasis siempre es un oasis, sobre todo si uno sale de un desierto de aburrimiento (2003:152).

Sí. Bolaño se refiere a Baudelaire en este fragmento muy parecido a aquel que sirve de epígrafe para 2666, su novela póstuma: "un oasis de horror en medio de un desierto de aburrimiento”. El pretexto del epígrafe es referirse a lo que este escritor denomina el hombre moderno y que puede ser ese hombre moderno que ha querido privilegiar la razón sobre las demás cosas, que ha habitado un siglo XX enfermizo y tocado por las guerras; que ha optado por privilegiar el mercado y las ideologías antes que a las personas; que ha pretendido colocar fronteras rigurosas en las ciencias y en las artes; que ha encarnado a la aristocracia en decadencia, a la burguesía y pequeña burguesía en ebullición, y al movimiento obrero siempre suplicante. Pero ese hombre puede ser, también, aquel que más allá de la modernidad, en la época de un capitalismo mucho más avanzado e influyente en todas las esferas de la vida, se ha rebautizado posmoderno y ahora es un ser desolado ante las inclemencias del mundo; un ser que vive bajo las intemperies de los trabajos temporales, de las hibridaciones de todo tipo, de la tiranía del mercado global y de las imágenes (y, por ende, de las apariencias y del culto al cuerpo) de la tecnodependencia, de la electrónica, de lo digital, de la eventualidad, de la cultura del espectáculo, de los neofundamentalismos, de las constantes mutaciones en los estilos, las costumbres, las interrelaciones; del reinado de los mass media, la publicidad y el marketing.

El epígrafe citado es, además, una mirada a ese mundo que irremediablemente condena a los hombres, que los sigue condenando hoy de igual manera a como el poeta francés denunciaba que los condenaba hace 150 años, y como otros han denunciado que los condenaba antes. O sea que el mundo parece no haber cambiado y de ahí surge la necesidad de que ahora otros escritores mantengan encendido el discurso de lo profano, de lo no ascético, de los descreimientos, como lo hacía Baudelaire —en esa época- al presentar, en ocasiones, una ambivalencia entre el cielo y el infierno, entre los ángeles y el demonio, entre la carnalidad y la espiritualidad, entre la realidad y la evocación, entre la salvación y la perdición, entre la conservación de la consciencia y la disgregación del yo que podría suceder, por ejemplo, al amor. 


\section{Escenarios y personajes de Roberto Bolaño en el entorno posmoderno}

_J'ai vu parfois, au fond d'un théâtre banal / Qu'enflammait l'orchestre sonore / Une fée allumer dans un ciel infernal / Une miraculeuse aurora / J'ai vu parfois au fond d'un théâtre banal...

El teatro banal parece ser la vida misma que engendra el spleen y sus tragedias y que, en este texto, se mueve entre lo infernal y lo celestial, entre el milagro y la caída, entre la resurrección y la muerte ¿№ es aquel teatro banal el mismo teatro del siglo XX con sus guerras y con sus inconsciencias, con sus mass media envolventes, con sus espiritualidades mal provistas? En la época de Roberto Bolaño, ese teatro banal se representa en todos los países y los actores no suelen ser estrellas al estilo hollywoodiano sino seres anónimos que se desangran cada día tocados por la violencia reinante en los lugares que habitan o en los caminos que recorren en un largo e insufrible viaje que los conduce al abismo y del cual buscan salvarse desesperadamente.

En la afirmación de Baudelaire sobre el desierto y el oasis, tomado del poema titulado precisamente El viaje, nadie libera al hombre de las potencias del mal. Bolaño, viajero irredento, la ha asumido también de tal manera. Así las cosas, después del desierto sigue el oasis que - en otros contextos- se lo ha querido asimilar a salvación, a escape de una muerte segura, a espacio reconfortante y purificador, pero que en estos dos autores significa explosión, caos, extravío e, incluso, otra forma de nombrar al mismo desierto. Y, por todo, eso significa condena; una nueva condena, irremediable, imprescriptible. Bolaño comenta el poema de donde extrae el epígrafe y manifiesta que

el viaje que emprenden los tripulantes del poema de Baudelaire en cierto modo se asemeja al viaje de los condenados. Voy a viajar, voy a perderme en territorios desconocidos, a ver qué encuentro, a ver qué pasa. Pero previamente voy a renunciar a todo. O lo que es lo mismo: para viajar de verdad los viajeros no deben tener nada que perder (2003:150).

¿Cuáles son los desiertos y cuáles los oasis de ese irredento viajero de apellido Bolaño que sale de Chile a los quince años, que en México lidera el grupo contestatario de los infrarrealistas, que luego se arrastra por Europa como alma en pena despreciando la literatura, pero creyendo en ella, y que a finales de los noventa da vida en Blanes — la misma Blanes de Últimas Tardes con Teresa (1990) de Juan Marsé, que él recuerda siempre con

\footnotetext{
2 "Yo a veces vi, en el fondo de un teatro banal / que la orquesta sonora inflamaba, / un hada que en un cielo infernal encendía / una alborada milagrosa; / yo a veces vi en el fondo de un teatro banal”. Charles Baudelaire. “L'irréparable”, en Les fleurs du mal (2006:243-246). Traducción de Alain Verjat y Luis Martínez de Melo.
} 
admiración - a otro viajero irredento, un alter ego de apellido Belano? ¿Cuáles los oasis y los desiertos de aquel escritor de apellido Bolaño que, también en Blanes, le cuenta a Javier Cercas, en la última parte de Soldados de Salamina (2001) la historia de un hombre de apellido Miralles que es veterano de muchas guerras?

\section{REMAKE DE ESCLAVIZADORES Y ESCLAVOS}

Respecto de lo anterior, la obra de Bolaño da muchas pistas porque sus personajes se mueven en esa concepción del mundo, en ese destino irrebatible signado por los hechos y por los hombres del siglo XX. Y, en consecuencia, los personajes de Bolaño son, a veces, esclavos y, a veces, esclavizadores, como sus referentes ineludibles en la realidad de tres dimensiones. Hay, entonces, en la humanidad de carne y hueso, quienes son el obrero negro que aparece en las doce escenas del mural $-\mathrm{y}$ que es probable que habite en el piso situado al otro lado de la pared- y hay, también, quienes son el constructor del edificio donde se pinta el mural. Y el pintor del mural. Y los noveles poetas que alimentan sus ilusiones en algún taller literario (Los detectives salvajes); la adolescente que al volver a casa es asesinada en la callejuela de cualquier ciudad (2666). Y el crítico que relee donde vaya a un afamado escritor (2666); y el citadino que va a un Sur que ya no es como el de Borges (El gaucho insufrible); y el cura que da clases de marxismo a los dictadores de derecha (Nocturno de Chile); y el hombre que gusta de hacer el amor en un cementerio (2666); y el detective contratado para buscar hasta el fin del mundo a alguien (no necesariamente el poeta-asesino) y darle muerte (Estrella distante) y el chileno de la izquierda silenciosa (Estrella distante); y el jorobado que se esconde en el bosque (Amberes); y la mujer que se oculta en los baños de la Universidad para evitar la represión militar (Amuleto); y el futbolista de los conjuros en Barcelona (Buba); y el productor de cine porno (Prefiguración de Lalo Cura); y el joven y su padre que se emborrachan y terminan envueltos en una riña absurda que conducirá a alguien a la muerte (Últimos atardeceres en la tierra).

La disyuntiva en el siglo XX —según Bolaño— es, entonces, ser esclavo o ser esclavizador; lo que hace pensar indefectiblemente en las violencias que campean impunes en todos los escenarios donde haya interrelación humana. Porque, para ocupar uno de esos lugares, o ambos, se convoca a aquellas violencias, que las hay de todo tipo, desde las ejercidas con brutalidad hasta las que parecen una sutil caricia y, entonces, no siempre la huella es un cadáver y puede ser, en cambio, el eco de una frase susurrada al oído o un revoltijo de cobijas en algún lecho. Esos temas pasan por Bolaño, quien los recrea con descarnamiento pero, también, con un refinado humor 


\section{Escenarios y personajes de Roberto Bolaño en el entorno posmoderno}

negro, como si uno y otro no tuvieran más remedio que pactar una alianza en el lenguaje para trascender. Los personajes de Bolaño terminan siendo, siempre, seres derrotados, independientemente de que sean esclavos o esclavizadores, de que estén en el desierto o en el oasis. Pero es probable que no se duelan de ello. Están derrotados porque no tienen salida y porque su prisión es, precisamente, el entorno que los rodea y, entonces, cualquier bifurcación en el camino es una trampa insalvable. Pero aprenden a aceptar y a convivir en ese entorno que muta de manera permanente y que se convierte en espacios que generan nuevas perplejidades y sutiles agresiones que deben aprender a superarse con celeridad.

En el mismo sentido, Jameson plantea que "como en toda la historia de las clases sociales, el trasfondo de la cultura lo constituyen la sangre, la tortura, la muerte y el horror” (1992:19). Bolaño también sostiene, parafraseando a Baudelaire, que el oasis es el horror. Y en él están implícitas todas sus derivaciones: el miedo, la huida, la perdición, la venganza, el odio, la apatía, el extravío, la exclusión, el dolor. Sí, el dolor. Un personaje de 2666 se detiene a reflexionar en ello: "Si no existiera el dolor, pensaba, seríamos perfectos. Insignificantes y ajenos al dolor. Perfectos, carajo. Pero allí estaba el dolor para chingarlo todo" (702). Otro personaje dice, en otro aparte de esa misma novela, que "toda la elocuencia es del dolor" (1075). Esto es válido para múltiples lugares pero, sin duda, América Latina es un escenario abonado especialmente para cualquier barbarie y Bolaño insiste en poner el dedo en la llaga. En esa lógica, el autor chileno recrea la dictadura de Pinochet quien — aunque se pusiera la máscara del desarrollo neoliberalactuaba, como todas las dictaduras y muchas democracias, con el lema de que "la muerte es limpieza" (2003:90). Y recrea, también, las tragedias en la frontera mexicano-estadounidense, donde las mujeres tienen "un trabajo mal pagado y explotado, con horarios de miedo y sin garantías sindicales, pero trabajo al fin y al cabo" (2666:710) y que algunos, quizás muchos, cínicamente se atreven a calificar como una bendición, mientras muy cerca viven a cuerpo de rey los integrantes de cárteles de todo tipo y para quienes el derroche es uno de sus distintivos. Allí todo termina irremediablemente por venirse abajo "en una de esas interminables caídas mexicanas, es decir, una caída pespunteada de tanto en tanto por una risa en sordina, por un disparo en sordina, por un quejido en sordina ¿Una caída mexicana? En realidad, una caída latinoamericana” (582). Y, además, recrea la desilusión de un mundo esplendoroso que dejó de serlo, incluso hasta en su agresividad, como podría resumirse en la historia del bonaerense que vuelve a la pampa y sólo

encuentra conejos y donde los gauchos no responden ya a los desafíos 


\title{
Juan Carlos Pino - Alexander Buendía
}

\begin{abstract}
Hasta aquí podemos llegar, dijo Pereda, y sacó su cuchillo. Durante unos segundos pensó que los gauchos harían lo mismo y que aquella noche se iba a cifrar su destino, pero los viejos retrocedieron temerosos y le preguntaron, por Dios qué le pasaba, qué le habían hecho ellos, qué mosca le había picado. La luz de la fogata concedía a sus rostros un aspecto atigrado, pero Pereda, temblando con el cuchillo en la mano, pensó que la culpa argentina o la culpa latinoamericana los había transformado en gatos (2003:45).
\end{abstract}

Definitivamente, los tiempos del Martín Fierro habían pasado, como habían pasado, también, los tiempos de Juan Dahlmann viajando al Sur —en el cuento homónimo de Borges - pero la muerte, la caída y el destino siguen renovándose eternamente aunque el escenario, siendo el mismo, parece devenir ahora en un paisaje degradado kitsch, acorde con los nuevos tiempos.

Es inevitable, entonces, trasegar hoy como esclavo o como zombi en ese desierto que es erigido por una realidad cuyos sentidos son reconstruidos con el emblema y los contenidos de los medios de comunicación, con las nostalgias reales o inventadas, o con las ya mencionadas violencias y opresiones. No obstante, como los escenarios cambian, las expresiones del dolor suelen cambiar, también, y ya no muestran el desgarramiento del grito de la pintura de Edvard Munch (1910) una pintura canónica del mundo moderno y muy elocuente en la expresión externa de los sentimientos internos. Para Jameson, “conceptos como la angustia y la alienación (y las experiencias a que corresponden, como en El grito) ya no son adecuadas en el mundo de lo posmoderno", en virtud de que "la fragmentación del sujeto desplaza a su alienación” (1995:36). ${ }^{3}$ Para Jameson, aquello es la Manisestación del ocaso de los afectos en la cultura posmoderna.

\section{UN MUNDO DE SILENCIOS Y EXTRAVÍOS}

Y sucede que el horror y el dolor, en el universo de Bolaño, están marcados por el silencio "que lee cartas sentado en un balcón”, un silencio que "esplende en los pasillos vacíos, en las radios que ya nadie escucha" (2002:97). Y tal silencio puede ser una manifestación del desafecto, de una liberación de las emociones y de los sentimientos. Varias escenas pueden servir de ilustración. Una: Max —en Putas asesinas - amordazado frente a la mujer que lo sacó de la televisión para asesinarlo y que no puede gritar

\footnotetext{
${ }^{3}$ Jameson considera que el cuadro de Edvard Munch representa, paradigmáticamente, "los grandes temas modernistas como la alienación, la anomia, la soledad, la fragmentación social y el aislamiento; es casi un emblema programático de lo que suele llamarse la era de la ansiedad” (1995:31-32).
} 


\section{Escenarios y personajes de Roberto Bolaño en el entorno posmoderno}

aunque ella le cuente que lo imagina desesperado antes del desenlace fatal: "Y por fin me ves y gritas. Yo estoy quieta y no sé de qué naturaleza es tu grito" (2005:128). Dos: En Estrella distante, los invitados a la casa donde se aloja Carlos Wieder y que le sirve de galería para una macabra exposición que deja sin palabras a todos: "Nos mirábamos y nos reconocíamos, pero en realidad era como si no nos conociéramos, parecíamos diferentes, parecíamos iguales, odiábamos nuestros rostros, nuestros gestos eran los propios de los sonámbulos o los idiotas” (2003:98). Tres: No grita Edwin Johns, el pintor que, luego de cortarse la mano con que pinta, la lleva a un taxidermista pensando que es aplicable a todo o a casi todo aquella ecuación de que "el dolor finalmente deviene vacío" (2666:76).

A los personajes de Bolaño, estén en el desierto o en el oasis, no les importa demasiado el extravío en las marismas del presente siempre eterno, porque, justamente, parecieran no tener o haber perdido una utopía, un arraigo cultural, familiar o geográfico, sentimental. Esa es la explicación para la lógica de las relaciones afectivas de tales personajes que están por fuera de cualquier convencionalismo, siempre sujetas a nada y expuestas, en cambio, a las expectativas de lo que pueda suceder sin premeditación. Y son inevitables, entonces, los encuentros casuales donde todos los actores tienen conciencia de la transitoriedad y de ser sólo piel y donde — por tal razón- el amor no tiene cabida o algún asomo de él puede convertirse en una verdadera catástrofe. Es la relación que establecen los personajes de Los detectives salvajes cuando se encuentran, sin siquiera planearlo, en público o en privado (los límites de estas dos esferas se han disuelto) y que, luego, igualmente se desencuentran, sin reproches y sin quejas. Son similares, en 2666, las coordenadas de la relación simultánea de Liz Norton con Jean Claude Pelletier y Manuel Espinoza, bajo la sombra literaria de Archimboldi, y similares las coordenadas de los jóvenes de Santa Teresa en los bares o en las casas donde se consumen en el sexo y en las drogas. Y son, también, las coordenadas de los incontables amores y desamores de Anne Moore, en Llamadas telefónicas, quien - en la turbulencia de su vida y de su trashumancia- prefiere callar porque "no tiene sentido añadir a este dolor más dolor o añadir al dolor tres enigmas diminutos. Como si el dolor no fuera suficiente enigma o como si el dolor no fuera la respuesta (enigmática) de todos los enigmas” (2003:202203). El mundo se plantea, así, como una entidad encriptada que ni siquiera vale la pena entender o, al menos, intentar entender. Hay que vivirlo y nada más. O, acaso, buscar un asidero que, en ocasiones, puede ser el arte. En Bolaño, buena parte de sus historias tienen como protagonistas a escritores o aprendices de escritores a quienes las palabras los salva de manera individual y que rechazan de plano todo convencionalismo. Los jóvenes del realvisceralismo en Los detectives salvajes son un ejemplo; pero lo es, también, el propio 
Archimboldi, nominado en un par de ocasiones al premio Nobel sin que a él le importe, perdido en su infinito trasegar desde la Alemania de los años veinte, pasando por su enlistamiento en el ejército alemán en el frente ruso o por su posterior trashumancia solitaria por diversos países. Y, también, es significativo que quienes, en apariencia, hallan una salvación, en el sentido tradicional del término, no son precisamente los artistas mismos, sino quienes hacen crítica y son estudiosos de sus obras —Norton, Pelletier, Morini, Espinoza, entre otros- lucrándose, además de ello, de igual manera a como hace Bruno en "El perseguidor", de Cortázar, quien sobrevive mientras el saxofonista prodigioso se hunde en el abismo. Otra manera de expresarse el pulso entre Dionisio y Apolo.

En síntesis, sería muy elocuente, entonces, que alguien se atreviera a pintar un mural callejero donde el hombre que aparezca en todas las escenas de un extraño reloj, no necesariamente circular, represente diferentes momentos de la vida artística. Es probable que no tuviera doce números (podrían ser más o menos, y no ser números sino colores o letras en algún lenguaje extraño) y el artista podría no ir vestido, cumpliendo no obstante diferentes funciones, y una de ellas podía ser tomada como la del payaso, "el tipo que está allí para hacernos reír” (2666:307) pero, también, en otra escena su función podría ser como la de un pensador que puede hacer llorar. Sin duda, sería la obra de un loco. "En el centro del reloj, donde convergían todas las escenas, había una palabra pintada con letras que parecían de gelatina” (307). Pero, esta vez, esa palabra no sería miedo, sino horror. O dolor.

Es muy probable que al otro lado del muro donde pudiera pintarse este hipotético mural, este pastiche posmoderno, habiten -como en una isla que cada vez es menos isla y más burbuja - personas evadiéndose consciente o inconscientemente del mundo, sin notar que aquella evasión es, también, una fragmentación, otra más, y que aquel individualismo patológico y la cero solidaridad pueden ser, también, una condena. Para aquellas personas (como para las del mural de Detroit que mira un hombre negro llamado Fate en la novela de Bolaño) el vecindario ya no está afuera sino adentro, en la red, como están los amigos, las mascotas, los deportes (PC Games, bicicletas estáticas, por ejemplo) y como está el mundo todo (los bancos, las oficinas, los despachos, el periódico, los ladrones). Y es muy probable que, como en los universos de Bolaño y de Baudelaire, en la aparente comodidad de aquel espacio se encuentren indelebles los desiertos de aburrimiento y los oasis de horror. 
Escenarios y personajes de Roberto Bolaño en el entorno posmoderno

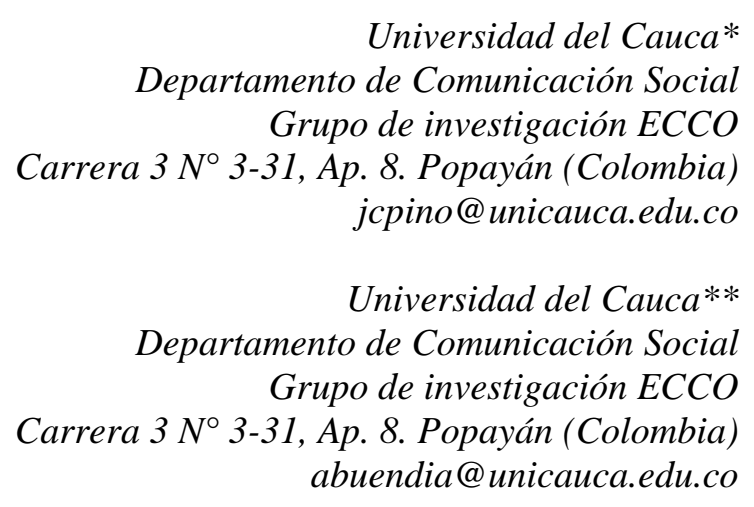

\section{BIBLIOGRAFÍA}

BAUDELAIRE, Charles. Les fleurs du mal. Madrid: Cátedra, 2006.

BOLAÑO, Roberto. 2666. Barcelona: Anagrama, 2007.

------- Nocturno de Chile. Barcelona: Anagrama, 2007.

------ Amuleto. Barcelona: Anagrama, 2007.

------- Los detectives salvajes. Barcelona: Anagrama, 2007.

------- Putas asesinas. Barcelona: Anagrama, 2005.

------ La literatura nazi en América. Barcelona: Seix Barral, 2005.

------ El Gaucho insufrible. Barcelona: Anagrama, 2003.

------- Estrella distante. Barcelona: Anagrama, 2003.

------- Llamadas telefónicas. Barcelona: Anagrama, 2003.

------- Amberes. Barcelona: Anagrama, 2002.

BOLAÑO, Roberto; PORTA, Antoni García. Consejos de un discípulo de Morrison a un fanático de Joyce. Barcelona: Acantilado, 2006.

BORGES, Jorge Luis. Obras completas I. Barcelona: RBA Instituto Cervantes, 2005.

CAMUS, Albert. El mito de Sísifo. Madrid: Alianza, 2006.

CERCAS, Javier. Soldados de Salamina. Barcelona: Tusquets, 2006.

CORTÁZAR, Julio. Obras Completas III. Barcelona: RBA Instituto Cervantes, 2006.

HERNÁNDEZ, José. Martín Fierro. Madrid: Alianza, 1996.

JAMESON, Fredric. El posmodernismo o la lógica cultural del capitalismo avanzado. Barcelona: Paidós, 1995.

------- Teoría de la Posmodernidad. Buenos Aires: Trotta, 1996.

MARSÉ, Juan. Últimas tardes con Teresa. Barcelona: Seix Barral, 1990.

SARAMAGO, José. Ensayo sobre la ceguera. Madrid: Alfaguara, 2002. 